\title{
TRACE ELEMENTS IN PASTURE AND THEIR EFFECTS ON ANIMAL HEALTH
}

\author{
E. D. ANDREWS \\ Wallaceville Animal Research Centre, Upper Hutt
}

Summary

Recent investigations into the biochemical functions of selenium, cobalt, and copper are reviewed. From a practical viewpoint there is a need for continued investigation into the distribution of the corresponding trace element deficiencies and their interrelationships with internal parasitism.

\section{INTRODUCTION}

IN THIS PAPER discussion is restricted to three trace elements, selenium, cobalt, and copper, that in some areas are required by grazing animals in amounts greater than those naturally available from pasture. However, although not discussed here, iodine as a means of controlling goitre is of importance in New Zealand, and the possible existence of other trace element deficiencies or imbalances (e.g., zinc or manganese) in feeds remains open for investigation.

Background information is not discussed in detail here.. Rather, more recent information is summarized and lines of investigation indicated that should prove interesting and profitable.

\section{SELENIUM}

Selenium-responsive diseases of animals in New Zealand were last reviewed some four years ago (Andrews et al., 1968) .

The biochemical function of the element is still not clear. In particular, the nature of the relationship between vitamin $E$ and selenium remains obscure. However, it now seems certain that seleno-amino acids, analogous to the sulphur amino acids, are not synthesized by animals. More probably, selenium forms complexes in which a selenium atom acts as a bridge between two adjoining sulphur atoms $\left(\mathrm{R}_{1}-\mathrm{S}-\mathrm{Se}-\mathrm{S}-\mathrm{R}_{2}\right)$. At Wallaceville progress has been made in identifying the proteins with which selenium is associated and marked differences have been found in the distribution patterns of selenium among protein fractions isolated from the organs of selenium-deficient and seleniumsupplemented rats (Millar et al., 1972). 
Interest attaches to the suggestion that the so-called Sudden Death in Infants Syndrome may be related to a relative deficiency of selenium and/or vitamin E in cows' milk (Money, 1970). Although direct evidence is lacking, a Wallaceville survey has shown that, as compared with cows' milk, human milk contains much more selenium and vitamin E (Millar and Sheppard, 1972).

Selenium-responsive unthriftiness in sheep is linked to concentrations of the element in soils, pastures, and animal tissues. Reduced growth rates are associated with selenium levels that average $<0.02 \mathrm{ppm} \mathrm{DM}$ in pastures and $<0.01 \mu \mathrm{g} / \mathrm{ml}$ in blood. Selenium dosing will raise the selenium content of wool by a factor of about 2 to 3 and values for wool from mildly deficient sheep average about $0.06 \mathrm{ppm}$.

Ruakura studies have shown that relatively large amounts of sodium selenite (up to about $9 \mathrm{~kg} / \mathrm{ha}$ ) can be incorporated into soils by a method that would be safe for stock and effective for a number of years (Van der Elst and Tetley, 1970). Wallaceville investigations indicate that sodium selenite at much smaller rates (about $38 \mathrm{~g} / \mathrm{ha}$ ), when mixed with superphosphate and spread on the surface, remains effective for about one year (A. B. Grant, pers. comm.). Current experiments suggest that sodium selenate, spread at an equivalent rate, may remain effective for longer $\mathrm{p}$ e $\mathrm{r}$ i o d s.

On a Taupo ash soil, selenium "bullets" (similar to cobalt bullets) resulted in a $7 \mathrm{~kg}$ mean weight response in young sheep. The patterns of response were similar, irrespective of whether the trial sheep were selected, before the start of the trial, on the basis of normal blood selenium levels (averaging about $0.020 \mu \mathrm{g} / \mathrm{ml}$ ) or low blood selenium levels $(0.008 \mu \mathrm{g} / \mathrm{ml})$. However, over a 12-month period, $15 \%$ of treated animals rejected their bullets and some bullets became coated with calcium phosphate.

During the past three years a limited number (30) of seleniumresponse trials with lambs have been carried out by field research officers of the Department of Agriculture. These showed that certain soils in the southern part of the North Island (Ohakea and Halcombe), in Nelson (Whakatu), in Westland (Lee and Harihari), and in Southland (Tuapeka and Waikoikoi), can be tentatively added to the list of soils classified as marginally selenium-deficient. Although the number of sheep trials was small, about $23 \%$ showed positive weight responses to selenium. In earlier experiments on pumice soils, calves showed marked responses to selenium in terms of reduced mortalities and increased weight gains. Nevertheless, there is still little information relating 
selenium status to calf growth on other soils (particularly those in the South Island) known to be selenium-deficient for sheep. Present evidence indicates that more extensive studies involving both cattle and sheep are warranted.

\section{COBALT}

An account of cobalt deficiency in sheep and cattle is given in the Department of Agriculture's Bulletin 180 (Andrews, 19'71).

The biochemical role of cobalt resides in its uniquely determined position in the vitamin $B_{12}$ molecule. This vitamin functions as a coenzyme in certain specific enzyme systems. In the sheep, one such system operates at a stage in the metabolism of propionate (Marston et al., 1961) an important source of energy for ruminants. In the deficient sheep, failure to convert methylmalonyl CoA to succinyl $\mathrm{CoA}$ results in a greatly increased excretion of methylmalonic acid (Gawthome, 1968; Andrews et al., 1970). Moreover, in the incipiently deficient animal, increased methylmalonic acid excretion occurs before overt signs of the disease appear (Andrews and Hogan, 1972). Present investigatians are directed toward the application of these findings to the laboratory diagnosis of cobalt deficiency.

It has long been known that, if the average cobalt content of pasture falls below certain critical levels (about $0.04 \mathrm{ppm}$ for cattle and $0.08 \mathrm{ppm}$ for sheep), cobalt deficiency disease may result. However, the diagnostic value of pasture analyses is limited by soil contamination in two ways. First, if samples are significantly contaminated, an apparently normal value may be wrongly interpreted since soil contains much more cobalt than the pasture it grows. Secondly, if washed samples are used or if clean samples are taken ahead of rotationally-grazed animals, a low result may mislead since, as discussed by Healy (1972), stock may derive considerable benefit from cobalt in soil adhering to pasture plants.

On cobalt-sufficient soils, different plant species may differ greatly in the amounts of cobalt they absorb; in particular, cobalt concentrations in clovers tend to be materially greater than those in grasses. However, in our experience (Andrews, 1966) differences between white clover and grasses tend to become negligible when those plants grow in association on cobalt-deficient soils.

It has been suggested that soils receiving annual applications of cobaltized superphosphate may, over a long period of years, accumulate reserves of cobalt available to pasture plants. Present 
indications are that this is so in some, though probably not in all, cases. However, the work is not yet completed and practical implications await assessment.

As compared with sheep, cattle are less susceptible to cobalt deficiency and in these latter the disease, nowadays, is thought to be rare. However, a few calf livers from North Auckland have shown relatively low vitamin $B_{12}$ reserves and the possibility remains that, in both 'cattle and sheep, other disease conditions might precipitate cobalt deficiency disease, if cobalt intakes were marginal.

Field reports and analytical results suggest that cobalt deficiency in young sheep continues to be rather widespread, though sporadic. Nevertheless, this evidence has received little support from results of recent national cobalt weight-response trials with lambs. However, these trials have been too few to enable any reliable assessment to be made, and further investigations, on key soils suspected of being marginally deficient, are needed.

\section{COPPER}

Recent overseas research indicates a new and exciting biochemical role for copper in the formation of normal connective tissue (Underwood, 1971). Copper deciency may result in reduced activity of the copper-containing enzyme, monoamine oxidase. As a consequence, the amino acid lysine fails to condense to form chemical cross-linkages between side chains that determine the integrity of the connective tissue protein elastin. A similar sequence is probably involved in the formation of collagen, the other important protein component of connective tissue.

These findings have been applied to experiments with young sheep grazing high-molybdenum pastures (Hogan et al., 1971). With the advent of spring, the molybdenum in pasture rises rapidly from a level of about $5 \mathrm{ppm}$ DM to about $20 \mathrm{ppm}$. As compared with copper-supplemented sheep, the growth rate of untreated animals slackens; a proportion of the latter develops bone fragility, and associated with this are connective tissue lesions that appear to be specific.

At Wallaceville the biochemistry of this copper-responsive syndrome is under investigation. Meanwhile, there are important practical implications that merit consideration. First soils that grow pastures naturally high in molybdenum are of considerable extent. Secondly, in terms of plant growth, soils classified as "molybdenum responsive" cover some millions of acres. Thirdly, 
molybdenized superphosphate is widely used. Fourthly, on certain Northland soils a copper-responsive condition may develop in dairy herds, a condition associated with haemoglobinaemia, poor thrift, and a marked reduction in milk yield (Basil Smith, pers. comm.), In some cases there is evidence of low copper status and/or a history of excessive use of molybdenized fertilizer.

Some features of the Northland disease remain obscure. However, there is no doubt as to its economic significance, and, on a national scale, production losses from molybdenum-conditioned copper deficiency, in both cattle and sheep, could be of considerable importance.

Plans to investigate the condition as it occurs in practice are still in the formative stages. However, several lines of investigation, in sequential order, suggest themselves:

(1) Documentation of molybdenum usage on a district and a farm basis.

(2) Sampling of pastures on suspect key soils for copper and molybdenum content.

(3) On key soils determining the effects of fertilizers on pasture molybdenum.

(4) Copper-response trials with animals.

\section{TRACE ELEMENTS AND INTERNAL PARASITISM}

Two recent experiments with young sheep, conducted at Wallaceville in two successive years, showed that internal parasitism was associated with significantly reduced concentrations of selenium, copper and vitamin $B_{12}$ in liver (Andrews et al., 1971) . In the cases of selenium and copper, the reduced values reached levels that could be consistent with impaired health resulting from the corresponding deficiency. However, in those two experiments liver vitamin $\mathrm{B}_{12}$ concentrations, although significantly lower for parasitized animals, did not reach levels indicative of cobalt deficiency disease.

In a third experiment involving young grazing sheep that ultimately became cobalt-deficient, a group that did not receive worm drenches showed a lower vitamin $B_{12}$ status than did an anthelmintic-treated group (Andrews \& al., 1970). However, differences did not attain statistical significance, possibly because the parasitized animals entered a stage of spontaneous recovery from worm infestation before the effects of cobalt deficiency became evident. Nevertheless, in terms of death rates and reduced 
weight gains, the overall effects of both diseases together were materially greater than those of either disease considered separately.

Internal parasites are a serious source of economic loss to the livestock industry. Similarly, insidious losses from deficiency diseases, that are now largely marginal in character and therefore difficult to detect, continue into the present time. Needs for intensified research into possible interactions between the two kinds of disease conditions, and translation of the results into practice are, I believe, clearly indicated.

\section{REFERENCES}

Andrews, E. D., 1966: N.Z. $/ l$ agric. R es., 9: 82938.

$$
\text { 1971: N.Z. Dept Agric. Bull. } 180 .
$$

Andrews, E. D.; Hartley, W. J.; Grant, A. B., 1968: N.Z. vet. J., 16: 3-17. Andrews, E. D.; Hogan, K. G., 1972: N.Z. vet. J., 20: 33-8.

Andrews, E. D.; Hogan, K. G.; Brunsdon, R. V., 1971: Proc. N.Z. Soc. Anim, Prod., 31: 65.

Andrews, E. D.; Hogan, K. G.; Stephenson, B. J.; White, D. A.; Elliott, D. C., 1970: N.Z. Jl agric. Res., 13: 950-65.

Gawthome, J. M., 1968: Aust. $J$. biol. Sci., 21: 789-94.

Healy, W. B., 1972: Proc. N.Z. Grassland Ass., 34: 84-90.

Hogan, K. G.; Money, D. F. L.; White, D. A.; Walker, R., 1971: N.Z. $l l$ agric. Res., 14: 687-701.

Marston, H. R.; Allen, Shirley H.; Smith, R. M., 1961: N ature, Lond., 190: 108591 .

Millar, K. R.; Sheppard, A. D., 1972: N.Z. $J l$ agric Res., 15: 3-15.

Millar, K. R.; Sheppard, A. D.; Gardiner, Mary Ann, 1972: N.Z. Il Agric. Res., 15: 756-77.

Money, D. F. L., 1970: N.Z. med. J, 71: 324.

Underwood, E. J., 1971: Trace Elements in Human and Animal Nutrition. 3rd ed., pp. 91-3. Academic Press, New York and London.

Van der Elst, Hupkens F. C. C.; Tetley, R., 1970: N.Z. Jl agric. Res., 13: 945-9. 